\title{
An Evaluation of Instructional Website Designs from the Perspective of Visual Perception Theories: A Study on Scale Development
}

\author{
Suzan Duygu Eristi \\ Anadolu University, Turkey \\ Ozden Sahin-Izmirli \\ Eskisehir Osmangazi University, Turkey \\ Serkan Izmirli \\ Anadolu University, Turkey \\ Mehmet Firat \\ Anadolu University, Turkey \\ Halil Ibrahim Haseski \\ Anadolu University, Turkey
}

\begin{abstract}
The purpose of this study was to develop a scale which could be used to evaluate instructional website designs from the perspective of visual perception theories. For this purpose, a scale of 50 items was developed based on the literature and expert opinions. Visual perception theories such as Gestalt Theory, Brunswick's Probabilistic Functionalism, Neuropsychological Theory, Theory of Direct Perception and Ecological Optics, Constructivist Visual Perception Theory and Computational Approach to Visual Perception provided a basis for the development of scale items; also a focus group discussion was employed. 196 students from the Computer Education and Instructional Technologies (CEIT) Department filled the scale. The exploratory factor analysis (EFA) was applied along with the principal component method on data. Following the factor analysis, a single factor scale was developed. The loading of each item in the scale was found to be over .30. The internal consistency coefficient of the overall scale was high $(\alpha=.961)$. The corrected item-total correlation coefficient of the items was .301 and over. Through factor analysis, it was revealed that the scale had a single-factor structure with an explained variance of $35 \%$. At the end of the study, several recommendations were presented for future studies.
\end{abstract}

Keywords: Visual Perception; Scale development; Instructional website; Factor analysis

\section{Introduction}

Perception covers a multi-component system which includes acquiring information pertaining to events, phenomena and concepts around us, sensing the stimuli and realizing the message 
conveyed by the perceived concept. In effect, perception can be described as the process of sensation and realization via senses (Demirel \& Un, 1987). Individual characteristics and social reflections play an active role during the perceptual process (Arnheim, 1974; Erinc, 1998). Individuals create a perceptual field within the social environment in line with their own characteristics, competencies and interests. Visual perception is the sensory awareness of a perceived concept and selecting, organizing and describing each particular stimulus holistically as parts of that concept by means of understanding its visual features (Behrens, 1984; Booth, 2003; Findlay \& Gilchrist, 2003). As it is the case in many other areas, in instructional contexts, perception and visual perception are two variants that play a decisive role in the instructional quality. For this reason, the characteristics of the perceiving audience and perceived concepts and in what manner the perception takes place are extremely important (Eidenberger, 2004; Messaris \& Moriarty, 2005). Instructional environment and designs are two fields in which the perceptual process should be put to work. Since instructional designs are considered as contexts where visual perception can particularly be created and where the instructional quality can be increased, they should be discussed and evaluated within the context of visual perception theories.

The boundaries of instructional designs have expanded greatly, and the teaching process has acquired a different dimension going beyond the classroom environment, thanks to recent technological developments. Designed virtually during today's teaching processes, teaching is capable of providing students with sustainable communication and interaction (Keser, Esgi, \& Simsek, 2003; Young, Barab, \& Garrett, 2000). When instructional designs are associated with the visual perceptual field, the instructional designs can be said to have many components integrated with perception theories - i.e. the efficiency in instructional designs are related to success of the design, thereby its visual quality. Within this context, it can be anticipated that an instructional design developed, evaluated and introduced under the framework of visual perception theories can meet the visual expectations of the student with its visual efficiency (Mirzoeff, 1998; Mullet \& Sano, 1995). When instructional designs are considered, it is possible to cite certain visual perception theories that can be put to work especially during the design, development and evaluation (Taverna, 2003).

The study sets out to determine criteria based on the fundamentals of visual perception theories whose efficiency has been pre-determined during the process of instructional design, development and evaluation. Another purpose of the study is to establish a scale based on these criteria. Within this context, at the first stage of the study, a multidimensional sum of criteria was created for the instructional design development and evaluation process by making use of principles founded on visual perception theories, and a study on scale development was carried out relying on these criteria. Visual perception theories, their general principles, and their relationships with the designing process discussed below within the scope of the study.

\section{Perception Theories and Design Process}

\section{Gestalt Theory}

Towards the end of $19^{\text {th }}$ century, Max Wertheimer, Kurt Koffka and Wolfgang Kohler introduced Gestalt perception theory as a result of their studies. Gestalt theory explains the visual perception, and the principle underlying the theory is "The whole is greater than the 
sum of the parts" (Senemoglu, 2005). According to famous Gestalt psychologist Kurt Koffka, the central task for perceptual science is to answer a simple question: Why do things look as they do? (Koffka, 1935). Modern theoretical approaches to perception, ecology, Connectionism and Cognitivism, answer this question starting from very different premises. Gestalt theory presents several laws; namely the Figure-Ground Relationship, Law of Proximity, Law of Similarity, Law of Closure, Law of Continuity, and Law of Simplicity which take their shape with this basic principle (Moore \& Fitz, 1993).

If the laws of Gestalt theory are to be discussed separately, it is seen that the figure-ground relationship explains the individual's focus of attention to visual stimulants. According to this law, the figure in visual stimulants is the part on which the individual focuses his/her attention. Ground, on the other hand, is the part that escapes attention and thus is outside the perceptual field. In line with this law, the information to be conveyed should be designed strikingly. Law of Proximity suggests that spatially and temporally proximal objects tend to be perceived through classification. Law of Similarity emphasizes that stimulants similar in many aspects such as form, color, structure, gender and so on tend to be co-perceived through classification. Law of Closure indicates that incomplete/partial activities, forms and sounds tend to be perceived as if they were complete. Law of Continuity shows that lines and stimulants moving in the same direction tend to be co-perceived through classification. Finally, Law of Simplicity suggests that stimulants tend to be perceived in their simplest forms (Hsiaoa \& Choub, 2006; Puustinen, Baker, \& Lund, 2006). Gestalt theory provides critical explanations for why visual perception principles can have a profound effect on the meaning of presented information. While gestalt principles of visual perception are easy to grasp, they are very powerful (Graham, 2008). Based on Gestalt Theory, some recent theories have emerged related to digital image analysis like computer vision. The technique of the Computer Vision approach is mathematical formalization of the Gestalt theory (Desolneux, Moisan \& Morel, 2008).

\section{Brunswick's Probabilistic Functionalism}

Brunswick's theory of Probabilistic Functionalism is based on the mind's interrelation between distal and proximal phenomena (Gordon, 2004). In other words, probabilistic functionalism theory advocates that the human mind is able to perceive objects in a much better way if this relationship is established on a proximal and distal basis. During this process, the objects are perceived depending on the intrinsic characteristics of those objects, the physical context that the objects are in, the intermediary between the object and the perceiver, perceiver him/herself and his/her own characteristics (Gordon, 2004), and these elements are active during the perceptual process.

A probabilistic functionalism-oriented design should suit the target group's characteristics; therefore, elements such as age, gender, cognitive, affective and readiness level of the target group should be taken into account. Furthermore, the prepared design should be suitable to the context where it is to be applied. Following the decision whether the message is to be given face-to-face or via computer presentation, the message should be designed in line with the selected medium. The design prepared in accordance with the probabilistic functionalism theory should meet the target group's expectations, so this means that it should be produced in parallel with learners' interests and expectations. This theory also puts emphasis on the role of the design in interaction between instructional material and target group. For this reason, 
all means of interaction and communication within the scope of the selected medium should be used actively for the instructional objective, and the learners should actively take part in the learning process. Since this theory suggests that objects are co-perceived based on proximal and distal relationship, associated elements should be presented together in design. Another principle that was defined by the theory is the fact that features of objects provide a clue for their own perception. Instructional elements which are designed accordingly should provide some clues on their functions or features (Brunswick, 1950; Brunswick, 1955; Gordon, 2004; Postman \& Tolman, 1959).

\section{Neuropsychological Approach to Visual Perception}

Neuropsychological approach presents a perspective based on nervous system and biological structure to visual perception. Any design prepared in line with this approach should provide the concentration of the target group, make sure that important piece of information is selected through selective attention, prevent the loss of attention and sustain it (Gordon, 2004; Wade \& Swanston, 1991).

The neuropsychological approach has principles that refer to design environment. "Design and its purpose should comply with each other". Any design to be produced according to this principle should be prepared in line with the information that is intended to be given to the target group. One of the principle of this theory, "suitability for target group", states that instructional designs should be prepared in order to suit cognitive, affective and psychomotor development levels of the target group. Since teaching is a communicative process, the principle of "quality of feedback" explains why the feedback given to learners regarding their learning levels should suit their interests in instructional designs. The principle of "correlating among design elements" underscores the necessity to prepare a design that would facilitate learning effectively and ensure the design integrity among its own elements. The principle of "Similar elements in design are co-perceived" states that elements which have similar features in terms of location, shape, color and function are co-perceived. The principle of "perceptual feature of design elements" marks that stimulants of the prepared pieces of design which appeal to different senses of the learners and which are used appropriately and timely during teaching process enhance the persistency of learning as well as the efficiency of the message. The principle of "ensuring integrity among design elements" explains that there should be integrity among design elements which will allow strong presentation of the message to be given. The principle of "features of emphasis in design" suggests that pieces of information which are considered crucial in design should be adjusted by putting highlighter visual features so that the learners' attention can be captured. The principle of "Design should generate motivation for design environment" stresses that produced designs should include stimulants suitable for the learners' needs and interests and generate motivation during learning process. The principle of "Design should help the target group achieve its goals and should create behavioral change" explicates that the prepared design should present a suitable content and interactive activities in accordance with the goals which are planned to be given. The principle of "Design should make sure that the state of teaching is permanent" points out that prepared designs should attract learners' attention and should be free of unnecessary stimulants and thus prevent distraction. The principle of "Design should evoke selected attention in perception within the target group" emphasizes that key points in prepared designs should be made easily perceivable for learners following their reorganization with different formal features. The principle of "Design should offer sustainable attention" indicates that prepared 
designs should include stimulants suitable for learners' expectations and development characteristics and sustain learners' attention during the learning process. The principle of "consistency of content" suggests that instructional content that is presented to the target group should have self-consistency and relevance (Gregory, Harris, \& Heard, 1995).

\section{Direct Perception and Ecological Optics}

J.J. Gibson, the founder of the Direct Perception and Ecological Optics Theory, underscores the fact that visual perception takes place over 3-dimension real actions - in contrast to the Constructivist Perception Theory and Gestalt Theory (Gibson, 1986; Michaels \& Carello, 1981). The theory - in general terms- puts forward suggestions such as moving visuals are more effective than static ones and objects' proximity and distance count for perception. Gibson's ecological psychology related to direct perception not only comprises a theory of how perception comes about but also contains a hypothesis on the objects of perception (Withagen \& van der Kamp, 2010).

Direct Perception and Ecological Optics Theory have principles that related to the design environment. According to these, the principle of "Design elements should match the overall purpose of design" explains that stimulants used in the designs should be capable of allowing the users to reach instructional goals of the design and that unnecessary elements should be avoided. The principle of "Design should support individual learning" states that prepared designs should not only suit the characteristics of the target group but also the individual characteristics of the users. The principle of "Designing the process should include applications related to instructional content" stresses that developed designs should include interactive applications that are compatible with the planned objectives, appeal to students' needs and interests, and help objectify the information to be learned. According to Jacobs and Michaels (2007), direct-perception and direct-learning approaches are based on the same principles, and it means that if direct perception is not supported, direct learning will not occur. The principle of "Feedback related to learning should be given" suggests that prepared instructional designs should contain activities which are good for defining the learning realization level such as repetitions and exercises or tests and that the student should be informed about his/her own activity. The principle of "Design objectives should be perceivable" emphasizes providing learners with instructional objectives clearly at the beginning of each subject for drawing their attention to key points. Finally, the principle of "Instructional activities and gains of the target group should be accessible and attainable" points out the importance of defining objectives which would match the introductory behavior and development level of the target group and activities which would help reach them (Cutting, 1982; Gibson, 1986; Gordon, 2004).

\section{Constructivist Visual Perception Theory}

The Constructivist Visual Perception Theory was put forward by Richard Gregory and suggests that individual differences and past experiences are active in perception and that the individual is actively involved in this process (Gillani, 2003). In other words, the individual selects the stimulants faced within the environment and perceives through interpretations with past experiences. 
The Constructivist Visual Perception Theory has several principles concerning the design environment. The principle of "Perception is active and constructional based on individual characteristics" explicates that designs should include interactive applications suitable for learners' individual characteristics such as age, gender and interests. The principle of "Individuals are not just passive recipient of knowledge" lays emphasis on the fact that designs should contain interactive applications, exercises and activities that will allow learners to be active participants in perception and learning processes. The principle of "Perception is affected by expectations, information, motivational and emotional factors" puts forth the need to know the target group's knowledge, opinions, attitudes and emotional characteristics regarding the subject to be taught in shaping designs produced in order to reach instructional objectives (Gombrich, 2002).

\section{Computational Approach to Visual Perception}

The Computational Approach was introduced by David Marr. The approach focuses on the actions of neural structures during the perceptual process and tries to explain visual perception through integration, correlation between context (where perception takes place) and features of the perceived concept and their reinterpretation (Gordon, 2004). According to the findings related to the computational approach, there is integrity in perception. In other words, despite the fact that objects' features such as their color, shape and moves are evaluated separately, they are brought together and make sense according to each individual's own cognitive and affective characteristics.

The design principles offered by the Computational Approach are as follows: The principle of "Vision and perception are processes of information processing" indicates that designs that take up and shape the subject contents in line with learners' preliminary knowledge and in connection with their past experiences ensure that instructional objectives are achieved. The principle of "Visible information is processed at low level, reproduced in order to represent the object and scene and each visible scene is combined in line with perception" explains that in prepared designs, the overall structure of the material and stimulants to be used - text, picture, graphics, animation and the like - should be designed in the simplest and most comprehensible way so that learners can achieve instructional objectives and learn effectively. The principle of "Having well-defined boundaries helps objects to diverge and be identified" emphasizes that in visual design, it is necessary to make use of appropriate delimiting design elements (lines, borders and so on) to make sure that pages have certain borders or that parallel bits of information are easily separated (Marr, 1982).

Above is the examination of basic visual perception theories through which visual design principles can be developed for instructional web sites. In the present study which aimed at evaluating instructional web pages, the visual perception theories reported in the related literature such as Gestalt Theory, Brunswick's Probabilistic Functionalism, Neuropsychological Theory, Theory of Direct Perception and Ecological Optics, Constructivist Visual Perception Theory and Computational Approach to Visual Perception were taken as basis. In the relevant literature, there are several tools developed for the evaluation of instructional web sites, while there is no evaluation tool developed specifically based on the visual perception theories. In this respect, this study is thought to contribute significantly to the visual design of instructional web sites. 


\section{Purpose of the Study}

The main purpose of this study was to develop a scale which can be used to evaluate educational website designs from the perspective of visual perception theories. In this respect, scale items were developed according to the visual design principles which were derived from the visual perception theories such as Gestalt Theory, Brunswick's Probabilistic Functionalism, Neuropsychological Theory, Theory of Direct Perception and Ecological Optics, Constructivist Visual Perception Theory, and Computational Approach to Visual Perception.

\section{Methodology}

\section{Participants}

Practitioners who work for integrating technology into education In Turkey are mostly graduates of Computer Education and Instructional Technologies (CEIT) Departments. CEIT curriculum in general consists of technology related courses such as software, hardware, graphics, animation, instructional design, material development and use of current technological tools. The courses also include the knowledge and skills necessary for integrating technology into education. Thus, the graduates are expected to produce visually advanced instructional software and others materials. Within this context, CEIT students are selected as participants who evaluated the website selected for this study from the perspective of visual perception theories.

Following the necessary official approval procedures in three state universities of Turkey (U1, U2, and U3), a total of 196 CEIT students with attendance of at least one semester answered the scale on a voluntary basis. 174 printed and 22 electronic scales were returned. 122 of the total participants $(62 \%)$ were male while $74(38 \%)$ were female. The ages of the participants ranged from 17 to 23 . Table 1 shows information about the students' class distributions for each university.

Table 1. Grades of students from each university

\begin{tabular}{crrrrrrrrrrr}
\hline University & & \multicolumn{1}{c}{ Year } & \multicolumn{3}{c}{ Total } \\
\hline & $\begin{array}{r}1^{\text {st }} \\
\text { year }\end{array}$ & $\%$ & $\begin{array}{r}2^{\text {nd }} \\
\text { year }\end{array}$ & $\%$ & $\begin{array}{r}3^{\text {rd }} \\
\text { year }\end{array}$ & $\%$ & $\begin{array}{r}4^{\text {th }} \\
\text { year }\end{array}$ & $\%$ & $\mathrm{n}$ & $\%$ \\
\hline U1 & 38 & 29,23 & 45 & 34,62 & 40 & 30,77 & 7 & 5,38 & 130 & 66,33 \\
\hline U2 & 3 & 5,45 & 9 & 16,37 & 23 & 41,82 & 20 & 36,36 & 55 & 28,06 \\
\hline U3 & - & 0 & 3 & 28,57 & - & 0 & 8 & 71,43 & 11 & 5,61 \\
\hline Total & 41 & 20,92 & 57 & 29,08 & 63 & 32,14 & 35 & 17,86 & 196 & 100 \\
\hline
\end{tabular}

At the end of 6 weeks of PhD courses, the instructional website was chosen to be evaluated by 196 CEIT students in three state universities from the perspective of visual perception theories. Four of the six course weeks were mainly spent on literature analysis, while one lesson was given based on experts' views and the last lesson week was given based on the participants' views. A team of four PhD students taking the course and the instructor found Turkish and English instructional websites during the first week. 
A total of 25 Turkish and 23 English websites were reviewed within the framework of the aforementioned visual perception theories. At the end of the evaluation process, which lasted three course weeks, three Turkish and seven English websites were found relevant. However, considering the possible differences in English levels of CEIT students and possible problems that would be caused by the lack of English proficiency, the idea to evaluate English websites was set aside. During the fourth week, it was realized that there was a problem in opening one of the three Turkish instructional websites via some Internet browsers, so website alternatives dropped to two.

During the fifth week, a focus group discussion on the study was held with a team of 10 members; one was a graphics and animation expert, one software development expert, one curriculum expert, one instructional design expert, one distance learning expert, one course instructor and four PhD students. Although the team put more emphasis on one site (S1), they failed to reach a clear agreement at the end of the focus group discussion. The websites (S1, S2) were not evaluated on a weak/strong basis in terms of visual perception theories taken into consideration within the scope of the study. The following week - the sixth course week-, a focus group discussion was held among 15 people including 10 CEIT senior students. The students evaluated S1 as functional (8 participants), successful in interface design (9 participants), appropriate in page layout (10 participants), learning supportive (7 participants) and easy to navigate (8 participants). They found S1 more successful than S2 from these aspects. The students who attended the focus group discussion were not involved in the study. As a result of these processes, S1 was determined as the website to be evaluated within the scope of the study from the perspective of perception theories.

\section{Data Collection Tool}

The researchers developed the "Evaluation Scale for Web-based Instructional Contexts" in order to evaluate web-based instructional contexts from the perspective of visual perception principles. The theories of Gestalt, Probabilistic Functionalism, Neuropsychological Approach, Direct Perception and Ecological Optics, Constructivist Visual Perception and Computational Approach to Visual Perception provided a basis for the preparation of the scale items. The focus group discussion method was used when creating the items of the scale which would allow evaluating an interactive media design from the perspective of perception theories. As a consequence of 6 sessions of focus group discussion, 8 experts (three experts working in graphic design and animation, two experts working in software development, two experts working in instructional design and one expert working in instructional methods field) determined 8 dimensions related to the evaluation of the websites namely page layout, color, typography, visuals (picture, graphics and photos), moving images (video, animation, simulation), navigation and browsing, content and functionality. These dimensions determined during the focus group discussions were reconsidered and correlated with theories resulting in the preparation of the sub-items. The correlation between the sub-items prepared during the focus group discussion of the study and the visual perception theories is as follows.

\section{Scale Items Produced in line with Gestalt Theory}

The visual perception scale developed for the study included items which were produced in line with Gestalt principles. The item 13 "Typographical elements and background where the 
elements are placed are arranged in a way to enhance legibility and perception" under the dimension of "Typography" was associated with the figure-ground relationship; the item 23 "Visuals found in design are used together with text content correlatively", the item 37 "Related links among navigation tools have been classified" under the dimension of "Visuals" and the item 34 "Moving images have been associated with instructional content and used with supportive information" under the dimension of "Navigation and browsing" were associated with the Law of Proximity; the scale item number "Colors of the design have been used in harmony with the correlated design elements" under the dimension of "Color" was associated with the Law of Similarity; and finally, the item 21 "Visuals found in design are clear and comprehensible preventing any different meaning" under the dimension of "Visuals" was associated with the Law of Simplicity.

\section{Scale Items Produced in line with Probabilistic Functionalism Theory}

The visual perception scale also included items in line with Probabilistic Functionalism. The item 7 "Design allows the user to apply personal coloring preferences" under the dimension of "Color" and the item 15 "Typographical elements used are suitable with the target group characteristics" under the dimension of "Typography" were associated with the principle of "Produced design should be suitable for target group"; and the item 31 "Moving images allow the user to interact and direct" under the dimension of "Moving Images" was associated with the principle of "Produced design is important for the interaction between the instructional material and the target group". Moreover, the item 22 "Visuals in design are self-consistent and able to be associated with the texts" under the dimension of "Visuals" was associated with the principle of "objects are perceived based on a proximal and distal relationship"; the item 43 "Instructional content constitutes a supportive integrity with the design elements" under the dimension of "Content" was associated with the principle of "design should be compatible with the context in which it is to be applied"; the item 36 "Redirection used in design work in parallel with the intended use" under the dimension of "Navigation and browsing" was associated with the principle of the theory "Features of the objects should provide clues for their perception".

\section{Scale Items Produced in line with Neuropsychological Approach}

The visual perception scale included a number of items consistent with the principles of the Neuropsychological Approach. The item 5 "Page layout is designed to facilitate the perception of the content and is free of unnecessary stimulants" under the dimension of "Page layout" and the item 47 "Design's speed of loading the screen does not cause any distraction" under the dimension of "Functionality" were associated with the principle of neuropsychological approach "sustainable attention" while the item 1 "Page layout has been configured within a certain system and integrity" was associated with the principle of "Ensuring integrity among design elements".

The item 6 "The color/s used in design has/have been configured within a certain system and continuity" under the dimension of "Color" and item 11 "The colors used in design are chosen among the ones which do not exhaust the user" were associated with the principle of "sustainable attention"; item 8 "The color/s used in design is/are able to highlight important information of the content" and the item 2 "Page layout is configured in a way to enable the 
user to focus on the bit of information intended to be learnt" under the dimension of "Page layout" were associated with the principle of "Design should evoke selected attention in perception among target group".

The item 12 "Stimulant typographical elements (bold, italic, underlined, animated etc.) have been used so that the user's attention is focused on important points of content" under the dimension of "Typography" was associated with the principle of "Features of emphasis in design" while the item 14 "Typographical elements have to be integral within themselves" was associated with the principle of "Ensuring integrity among design elements".

The item 19 "Visuals found in design are capable to keep the target group's attention alive in terms of their content and messages" under the dimension of "Visuals" was associated with the principle of "Design should make sure that state of teaching is permanent" and the item 30 "Moving images are self-coherent within design and thus do not cause any different meaning" under the dimension of "Moving Images" were associated with the principle of "Ensuring integrity among design elements". The item 24 "Visuals found in design emphasize the important bits of information of instructional content" was associated with the principle of "features of emphasis in design".

While the item 29 "The use of any unnecessary and distracting animated pictures has been avoided in design" under the dimension of "Moving Images" was in line with the principle of the theory of "sustainable attention", the item 32 "Moving pictures appeal to more than one perception channel" was in line with the principle of "perceptual feature of design elements". The item 38 "Interrelated redirections are presented in a certain classification within themselves" under the dimension of "Navigation and browsing" was prepared in line with the principle of "similar elements are co-perceived" and the item 27 "Moving images are compatible with instructional objectives and content" was associated with the principle of "Design and its objective should be compatible". The item 45 "Design should provide guidance to users on learning liabilities and in what way it is possible to efficiently make use of design" under the dimension of "Functionality" was associated with the principle of the theory "Design should help target group achieve its objectives".

\section{Scale Items Produced in line with Direct Perception and Ecological Optics}

The item 20 of the scale prepared "Visuals found in design enable the content to be perceived and objectified" under the dimension of "Visuals" was produced in line with the principle of the theory "Instructional activities and gains should be accessible and objectified" and the item 26 "Visuals in perception have features (depth, distance, proportion and perspective) that are perceivable and learning supportive" under the dimension of "Visuals" was associated with the core principle of the theory suggesting that visual perception takes place over 3-dimension real actions.

The item 44 "Content offers the students an opportunity for self-evaluation with its qualified feedback features" under the dimension of "Content" was associated with the principle of the theory "Feedback related to learning should be provided" and the item 40 "Objectives of instructional content have been stated clearly in design" was prepared in line with the principle of "Design objectives should be perceivable". 
The scale item 39 "The user is able to proceed according to his/her own learning speed" under the dimension of "Navigation and browsing" and the item 50 "Design has options which enable the user to save, store and load his/her own learning process" under the dimension of "Functionality" were associated with the principle of "Design should support individual learning". Finally, the item 48 "Image and resolution quality of design facilitates perception" under the dimension of "Functionality" was prepared in line with the principle of "Visual perceptibility of design facilitates learning".

\section{Scale Items Produced in line with Constructivist Visual Perception Theory}

The item 3 of the prepared visual perception scale "Page layout enables users to modify it as they wish and prefer" under the dimension of "Page layout" was prepared in line with the principle of the theory "Perception is active and constructional being based on individual characteristics". The item 17 "Visuals in design are qualified to provide motivation for instructional content" and the item 18 "Perceptibility of visuals in design match the levels and readiness of the users" under the dimension of "Visuals" and the item 28 "Moving images are qualified to provide interest and motivation for instructional content" under the dimension of "Moving images", the item 33 "Moving images are suitable for target group's level" and the item 10 "Colors used in design are chosen the ones which make motivation for instructional content possible" under the dimension of "Color" were all associated with the principle of "Perception is affected by expectations, information, motivational and emotional factors". The item 35 of the prepared scale "Design redirecting is user-oriented" under the dimension of "Navigation and browsing" and the item 41 "Content is supported by visual, audio and audiovisual elements and configured to enable interaction" under the dimension of "Content" and the scale item 49 "Design has an infrastructure that offers users the chance to upload and download files, to use applications such as e-mail, forum etc." under the dimension of "Functionality" were all associated with the principle of "Individuals are not just passive recipient of knowledge".

\section{Scale Items Produced in line with Computational Approach}

The item 25 of the prepared scale "Visuals found in design are carefully arranged in an order to facilitate identification and perception" under the dimension of "Visuals" and the item 42 "Instructional content is arranged and classified in accordance with instructional objectives" under the dimension of "Content" and the item 16 "Spaces among typographical elements (letters, words and line spaces) are qualified to provide perceptibility and distinguishability" under the dimension of "Typography" were all prepared in line with the principle of the theory "Having well-defined limits helps objects to diverge and be identified". The item 4 "Page layout has been designed to provide ease-of-use" under the dimension of "Page layout" and the item 46 "Design is easy to use" under the dimension "Functionality" were associated with the principle of "Designs should be produced in the simplest and most comprehensible way".

Exploratory factor analysis was performed within the study based on the purpose of developing a scale which would evaluate instructional websites that can be defined as instructional designs from the perspective of visual perception theories.

The four-point Likert scale had totally 50 items consisting of 5 items on page layout, 6 items on color, 10 items on visuals, 8 items on moving images, 5 items on navigation and browsing, 5 
items on content and 6 items on functionality. The Likert spaces of the scale were defined as "Strongly Agree", "Agree", "Partly Agree" and "Strongly Disagree". For the scope and format conditions of the developed form, one expert in instructional design, one expert in instructional technology and one expert in animation were consulted. The form was finalized and made ready after the views of field experts. The internal consistency coefficient of the scale was discovered to be $(\alpha=.961)$.

\section{Procedures}

\section{Pilot Study}

A pilot study was carried out in April 2010 with 21 students of CEIT Department in order to find out the response duration for the scale and to reveal whether the scale items were comprehended or not. The students filled in the scale in the computer lab upon reviewing the website (S1) which was selected by the researchers. The students completed the scales in a range of 17 to 33 minutes. The internal consistency coefficient of the scale following the pilot study was found to be high $(\alpha=.941)$. Following the pilot study, some items were revised and the final version of the scale was produced.

\section{Actual Study}

The data pertaining to the present study were collected between May and June 2010. The scale was applied to teacher candidates who were still students of CEIT Departments at three state universities at the time of the study with a response-duration of 21 to 30 minutes. The majority of the scales ( 174 pcs) were applied to the students by the researchers in computer labs. The students were asked to review the website chosen by the researchers and to fill in the scale. The researchers also prepared the digital form of the scale and sent them via e-mail and the URL address of the digital form to the students who failed to take part in the study in person. The number of the electronically-filled scales was 22. Within the study, a total of 196 scales were collected, 174 of which were printed and the rest 22 were digital. Following data collection, exploratory factor analysis was conducted through SPSS 15.0 program to assess the scale's factor structure.

\section{Findings}

The adequacy of the research data for factor analysis was tested according to certain criteria, the first of which was the sample size. For factor analysis, a sample size of 50 participants are regarded as "very poor", 100 participants as "poor", 200 participants as "fair", 300 participants as "good", 500 participants as "very good" and 1000 participants (or over) as "excellent" (Comrey and Lee, 1992). Kline (1994), on the other hand, points out that it is essential to have at least 100 participants for factor analysis. 196 participants within this study can be said to be adequate for factor analysis. The second step to determine the adequacy of the sample size was to check Kaiser-Meyer-Olkin (KMO) value, which is between 0 and 1. Pallant (2001) suggests that KMO has to be .60 and over, while Hutcheson and Sofroniou (1999) regard a $\mathrm{KMO}$ value between 0.5 and 0.7 as 'normal', between 0.7 and 0.8 as 'good', between 0.8 and 0.9 as 'great' and finally over 0.9 as 'superb'. The KMO value in the present analysis was .921, in the range of 'superb' value according to Hutcheson and Sofroniou (1999). The final criterion 
to check the adequacy of data for factor analysis was a significant value of Bartlett's Test of Sphericity. Bartlett's Test of Sphericity was found significant in the study $(p=.0001)$. The approximate Chi-square value was 5170,088. To sum up, the research data were adequate for factor analysis.

Eigenvalue of 11 components was over 1 at the end of the principal component analysis, and this fact explains $63.570 \%$ of total variance. However, the principal factor explains $35.170 \%$ of total variance. While eigenvalue of principal factor was 17.585 , the others' value ranged from 1.011 to 2.158 . A process was followed in order to eliminate the inappropriate scale items. The corrected item-total correlation values of the items were checked and found to range from .301 to .671. The corrected item-total correlation value should not be less than .30 (Pallant, 2001); that is to say, the corrected item-total correlation values of all the items were appropriate. The item loading of the scale items was between .306 and .694. Pallant (2001) puts forth that items with an item loading over .30 should not be eliminated. It is seen that all the items showed a single factor structure. An explained variance of $30 \%$ and more in singlefactor scales are regarded as adequate in social sciences (Bayram, 2004; Buyukozturk, 2002). The single factor scale's validity was adequate in this study with an explained variance of $35.170 \%$. The internal consistency coefficient of the 50 -item scale was found to be high $(\alpha=.961)$. Table 2 demonstrates item statistics such as mean, standard derivation, item-total correlations and item loadings.

Table 2. Item statistics

\begin{tabular}{|c|c|c|c|c|c|}
\hline \multicolumn{2}{|c|}{ Items } & \multirow{2}{*}{$\frac{\text { Mean }}{2,94}$} & \multirow{2}{*}{$\frac{\text { SD }}{0,85}$} & \multirow{2}{*}{$\begin{array}{c}\begin{array}{c}\text { Item- } \\
\text { total } r\end{array} \\
0,671\end{array}$} & \multirow{2}{*}{$\begin{array}{c}\begin{array}{c}\text { Item } \\
\text { loading }\end{array} \\
0,694\end{array}$} \\
\hline 30 & $\begin{array}{l}\text { Moving images are self-coherent within design and thus do } \\
\text { not cause any different meaning }\end{array}$ & & & & \\
\hline 18 & $\begin{array}{l}\text { Perceptibility of visuals in design matches the levels and } \\
\text { readiness of the users. }\end{array}$ & 2,84 & 0,80 & 0,659 & 0,683 \\
\hline 43 & $\begin{array}{l}\text { Instructional content constitutes a supportive integrity } \\
\text { with the design elements. }\end{array}$ & 2,96 & 0,80 & 0,663 & 0,681 \\
\hline 41 & $\begin{array}{l}\text { Content is supported by visual, audio and audio-visual } \\
\text { elements and configured to enable interaction. }\end{array}$ & 2,90 & 0,85 & 0,654 & 0,674 \\
\hline 28 & $\begin{array}{l}\text { Moving images are qualified to provide interest and } \\
\text { motivation for instructional content. }\end{array}$ & 2,92 & 0,88 & 0,649 & 0,673 \\
\hline 22 & $\begin{array}{l}\text { Visuals in design are self-consistent and able to be } \\
\text { associated with the texts. }\end{array}$ & 3,01 & 0,86 & 0,642 & 0,670 \\
\hline 21 & $\begin{array}{l}\text { Visuals found in design are clear and comprehensible } \\
\text { preventing any different meaning. }\end{array}$ & 2,99 & 0,80 & 0,639 & 0,665 \\
\hline 20 & $\begin{array}{l}\text { Visuals found in design enable the content to be perceived } \\
\text { and objectified. }\end{array}$ & 2,91 & 0,84 & 0,642 & 0,664 \\
\hline 34 & $\begin{array}{l}\text { Moving images have been associated with instructional } \\
\text { content and used with supportive information }\end{array}$ & 2,86 & 0,97 & 0,636 & 0,659 \\
\hline 4 & Page layout has been designed to provide ease-of-use. & 3,16 & 0,85 & 0,629 & 0,656 \\
\hline
\end{tabular}




\begin{tabular}{|c|c|c|c|c|c|}
\hline 26 & $\begin{array}{l}\text { Visuals in perception have features (depth, distance, } \\
\text { proportion and perspective) that are perceivable and } \\
\text { learning supportive. }\end{array}$ & 2,82 & 0,88 & 0,634 & 0,656 \\
\hline 14 & $\begin{array}{l}\text { Typographical elements have to be integral within } \\
\text { themselves (Such as using the same or similar fonts or } \\
\text { colors for interrelated texts, topics and explanations) }\end{array}$ & 3,03 & 0,80 & 0,622 & 0,649 \\
\hline 27 & $\begin{array}{l}\text { Moving images are compatible with instructional } \\
\text { objectives and content. }\end{array}$ & 3,05 & 0,90 & 0,623 & 0,648 \\
\hline 1 & $\begin{array}{l}\text { Page layout is configured within a certain system and } \\
\text { integrity. }\end{array}$ & 3,10 & 0,69 & 0,620 & 0,642 \\
\hline 17 & $\begin{array}{l}\text { Visuals in design are qualified to provide motivation for } \\
\text { instructional content. }\end{array}$ & 2,87 & 0,85 & 0,610 & 0,634 \\
\hline 31 & Moving images allow the user to interact and direct. & 2,87 & 0,92 & 0,611 & 0,630 \\
\hline 29 & $\begin{array}{l}\text { The use of any unnecessary and distracting moving images } \\
\text { has been avoided in design. }\end{array}$ & 3,04 & 0,85 & 0,598 & 0,626 \\
\hline 2 & $\begin{array}{l}\text { Page layout is configured in a way to enable the user to } \\
\text { focus on the bit of information intended to be learnt. }\end{array}$ & 3,03 & 0,69 & 0,596 & 0,624 \\
\hline 19 & $\begin{array}{l}\text { Visuals found in design are capable to keep the target } \\
\text { group's attention alive in terms of their content and } \\
\text { messages. }\end{array}$ & 2,85 & 0,93 & 0,600 & 0,623 \\
\hline 24 & $\begin{array}{l}\text { Visuals found in design emphasize the important bits of } \\
\text { information of instructional content. }\end{array}$ & 2,93 & 0,81 & 0,597 & 0,621 \\
\hline 36 & $\begin{array}{l}\text { Redirection used in design work in parallel with the } \\
\text { intended use. }\end{array}$ & 3,09 & 0,81 & 0,597 & 0,620 \\
\hline 23 & $\begin{array}{l}\text { Visuals found in design are used together with text content } \\
\text { correlatively (Providing references or links in texts etc.). }\end{array}$ & 2,89 & 0,87 & 0,591 & 0,619 \\
\hline 33 & Moving images are suitable for the target group's level. & 2,92 & 0,89 & 0,592 & 0,619 \\
\hline 44 & $\begin{array}{l}\text { Content offers the students an opportunity for self- } \\
\text { evaluation with its qualified feedback features (Repetition, } \\
\text { exercise, test etc.). }\end{array}$ & 2,87 & 0,90 & 0,597 & 0,617 \\
\hline 9 & $\begin{array}{l}\text { Colors of the design have been used in harmony with the } \\
\text { correlated design elements. }\end{array}$ & 2,86 & 0,85 & 0,593 & 0,616 \\
\hline 40 & $\begin{array}{l}\text { Objectives of instructional content are clearly stated in } \\
\text { design. }\end{array}$ & 3,08 & 0,79 & 0,586 & 0,612 \\
\hline 46 & Design is easy to use. & 3,08 & 0,82 & 0,567 & 0,593 \\
\hline 15 & $\begin{array}{l}\text { Typographical elements used are suitable with the target } \\
\text { group characteristics. }\end{array}$ & 2,85 & 0,83 & 0,573 & 0,592 \\
\hline 32 & $\begin{array}{l}\text { Moving pictures appeal to more than one perception } \\
\text { channel. }\end{array}$ & 2,75 & 0,90 & 0,565 & 0,590 \\
\hline 39 & $\begin{array}{l}\text { The user is able to proceed according to his/her own } \\
\text { learning speed (Browsing and navigation are under } \\
\text { student's control). }\end{array}$ & 3,04 & 0,81 & 0,560 & 0,589 \\
\hline 16 & $\begin{array}{l}\text { Spaces among typographical elements (letters, words and } \\
\text { line spaces) are qualified to provide perceptibility and } \\
\text { distinguishability. }\end{array}$ & 3,00 & 0,76 & 0,558 & 0,587 \\
\hline
\end{tabular}




\begin{tabular}{|c|c|c|c|c|c|}
\hline 37 & $\begin{array}{l}\text { Related links among navigation tools have been classified } \\
\text { (Classification through color, providing link or using in the } \\
\text { same location). }\end{array}$ & 3,02 & 0,81 & 0,557 & 0,586 \\
\hline 12 & $\begin{array}{l}\text { Stimulant typographical elements (bold, italic, underlined, } \\
\text { animated etc.) have been used so that the user's attention } \\
\text { is focused on important points of content. }\end{array}$ & 3,01 & 0,87 & 0,562 & 0,585 \\
\hline 8 & $\begin{array}{l}\text { The color/s used in design is/are able to highlight } \\
\text { important information of the content. }\end{array}$ & 2,76 & 0,88 & 0,561 & 0,580 \\
\hline 35 & Design redirecting is user-oriented. & 3,03 & 0,81 & 0,552 & 0,573 \\
\hline 45 & $\begin{array}{l}\text { Design should provide guidance to users on learning } \\
\text { liabilities and in what way it is possible to efficiently make } \\
\text { use of the design. }\end{array}$ & 2,89 & 0,76 & 0,543 & 0,565 \\
\hline 10 & $\begin{array}{l}\text { Colors used in design are chosen the ones which make } \\
\text { motivation for instructional content possible. }\end{array}$ & 2,65 & 0,87 & 0,540 & 0,555 \\
\hline 42 & $\begin{array}{l}\text { Instructional content is arranged and classified in } \\
\text { accordance with instructional objectives. }\end{array}$ & 3,13 & 0,77 & 0,528 & 0,549 \\
\hline 38 & $\begin{array}{l}\text { Interrelated redirections are presented in a certain } \\
\text { classification within themselves (buttons, menus, menu } \\
\text { subheadings etc.). }\end{array}$ & 3,08 & 0,78 & 0,524 & 0,545 \\
\hline 13 & $\begin{array}{l}\text { Typographical elements and background where the } \\
\text { elements are placed are arranged in a way to enhance } \\
\text { legibility and perception. }\end{array}$ & 3,07 & 0,73 & 0,517 & 0,540 \\
\hline 25 & $\begin{array}{l}\text { Visuals found in design are carefully arranged in an order } \\
\text { to facilitate identification and perception (using frames and } \\
\text { highlighters etc.). }\end{array}$ & 2,82 & 0,89 & 0,509 & 0,532 \\
\hline 3 & $\begin{array}{l}\text { Page layout enables users to modify it as they wish and } \\
\text { prefer. }\end{array}$ & 2,88 & 0,91 & 0,490 & 0,508 \\
\hline 11 & $\begin{array}{l}\text { The colors used in design are chosen among the ones } \\
\text { which do not exhaust the user. }\end{array}$ & 3,13 & 0,76 & 0,476 & 0,501 \\
\hline 48 & $\begin{array}{l}\text { Image and resolution quality of design facilitates } \\
\text { perception. }\end{array}$ & 3,04 & 0,83 & 0,476 & 0,499 \\
\hline 6 & $\begin{array}{l}\text { The color/s used in design has/have been configured } \\
\text { within a certain system and continuity. }\end{array}$ & 3,08 & 0,80 & 0,467 & 0,494 \\
\hline 5 & $\begin{array}{l}\text { Page layout is designed to facilitate the perception of the } \\
\text { content and is free of unnecessary stimulants. }\end{array}$ & 3,16 & 0,82 & 0,459 & 0,493 \\
\hline 47 & $\begin{array}{l}\text { Design's speed of loading the screen does not cause any } \\
\text { distraction. }\end{array}$ & 2,90 & 0,87 & 0,401 & 0,417 \\
\hline 50 & $\begin{array}{l}\text { Design has options which enable the user to save, store } \\
\text { and load his/her own learning process. }\end{array}$ & 2,69 & 0,99 & 0,410 & 0,416 \\
\hline 49 & $\begin{array}{l}\text { Design has an infrastructure that offers users the chance to } \\
\text { upload and download files, to use applications such as e- } \\
\text { mail, forum etc. }\end{array}$ & 2,80 & 0,91 & 0,403 & 0,412 \\
\hline 7 & $\begin{array}{l}\text { Design allows the user to apply personal coloring } \\
\text { preferences. }\end{array}$ & 2,07 & 1,02 & 0,301 & 0,306 \\
\hline
\end{tabular}




\section{Discussion and Conclusion}

The scale developed for this study meets the requirements of statistical analyses in terms of the number and variety of participants. 196 students in three state universities in Turkey cooperated in order to decide on the final scale items. Despite the fact that there are many studies on website design principles in the literature, most of them are solely based on Gestalt laws. However, this study reviews the principles of theories and approaches such as Gestalt, Probabilistic Functionalism, Neuro-psychological approach, Direct Perception and Ecological Optics, Constructivist Visual Perception Theory and Computational Approach, and develops a single factor scale.

Perceptional design principles play a leading role in the development of instructional designs. Especially the rapidly-spreading Internet and the increasing number of learning environments on the Internet have increased expectations regarding the design of web sites developed for instructional purposes. It could be stated that the scale developed within the scope of the present study allows us to evaluate educational interactive environments comprehensively.

Within the scope of visual perception theories in related literature, studies on the examination of instructional web sites generally focus on such principles of figure-ground relationship, proximity, similarity and completion within the frame of Gestalt visual perception theories (Hsiaoa \& Choub, 2006; Mirielli, 2007; Puustinen, Baker, \& Lund, 2006). However, especially in the educational design process, it is crucial to examine each phase of the design considering different dimensions of the design process. In the study, different from the literature, the reason for taking the other perception theories apart from Gestalt perception theory into consideration was the fact that the stated perception theories, especially when related with an interactive design environment, provide designers with the opportunity examine in more detail. Gestalt perception theory allows evaluating the perceptional effect of the whole design. While focusing on the effect of the design as a whole, the details could go unnoticed. In this respect, the other perception theories mentioned in the study led to detailed examination of different dimensions of the design process.

In the study, according to Egon Brunswick's functionalism approach, the prominent dimension was determined as functionalism, which is quite important for the audience. Within the scope of the probabilistic functionalism theory, a relationship was established between not only functionalism and perception in the context of the audience qualities but also functionalism and perception in the presentation of content. For perception to occur, Marr's computational theory features the integration of the qualities of the perceiving audience and the perceived environment. In this respect, the audience is taken into consideration within the context of the effect created both individually and as a whole with each design element within the design process. Here, Marr's computational theory suggests that a number of design elements - from animated images to visuals used in the content and from the use of colors to typography - be individually related with the audience and that accordingly the contents be handled separately and then re-interpreted as a whole. The neuro-psychological approach can be directly related with the main dimension of composition for determining various items that could be related with the hierarchy of such dimensions as planning the whole, determining the activities and presenting the content. The Constructivist Visual Perception Theory features individual differences of users. Here, both creating the content and relating the design elements and functionalism as well are related with the constructivist theory. Gibson's direct perception approach handles perception within the scope of the environment of the perceiving individual. 
Thus, such environmental factors as the meanings of the design elements presented in the content, the effect they will have on the audience and the qualities of the audience should also be taken into consideration in the presentation process.

This scale development study has a unique value in terms of continuous consultations held with field experts and detailed theoretical questioning. Upon studying visual perception theories, a team of 10 people worked for six weeks in order to develop design principles intended for websites. Additionally, a focus group discussion of 15 people - 10 of whom were CEIT senior students - was held during the website selection process. The first stage of the process was to decide on one Turkish and one English website out of 48 (in both languages) and then finally one website.

Experts in areas such as graphics/animation, software development, instructional programs, instructional design, distance learning, one instructor and $4 \mathrm{PhD}$ students joined the team in order to enhance the validity and reliability of the scale items. This team established 50 design principles that were classified under 8 headings namely page layout, color, typography, visuals, moving images, navigation\&browsing, content and functionality. Furthermore, the internal consistency coefficient of the scale during the pilot study which was conducted by 21 CEIT students was found to be high $(\alpha=.941)$.

Following the factor analysis of the items that were established on the design principles of perception theories, it was very clear that the items were collected under a single factor with an explained variance of $35 \%$. This result is parallel with the results of Palmer's (2002) threestep study Web Site Usability, Design, and Performance Metrics which was conducted respectively in 1997, 1999 and 2000. Palmer made some measurements related to websites' usability, design and performances as well as website content interaction and response, underscoring that the measurements of the stated aspects were parallel and could be evaluated under the same heading. Similarly, Treiblmaier and Pinterits (2010) developed another scale through exploratory factor analysis in a study undertaken with the Internet users on website content and designs; items established in the scale were grouped under only two factors, which were "entertainment \& design" and "information".

The scale developed within the scope of the study is considered very useful tool for both practical applications and scientific studies. Henceforth, it is possible to conduct experimental research on large and various target groups by making use of the website design principles produced for this study based on different visual perception theories. It is possible to further examine the opinions of users with different demographic backgrounds as to website designs by using items obtained during the scale development process.

\section{References}

Arnheim, R. (1974). Art and visual perception: A psychology of the creative eye. Berkeley, CA: University of California Press.

Bayram, N. (2004). Sosyal bilimlerde SPSS ile veri analizi [Data analysis with SPSS in social sciences]. Bursa: Ezgi Kitabevi.

Behrens, R. (1984). Design in the visual arts. Englewood Cliffs, NJ: Prentice-Hall.

Booth, R.G. (2003). Perception of the visual environment. New York: Springer. 
Brunswick, E. (1950). The conceptual framework of psychology. In O. Neurath (Ed.) International Encyclopedia of Unified Science, 1(10), 16-33.

Brunswick, E. (1955). Representative design and probabilistic theory in a functional psychology. Psychological Review, 62(3). 193-217.

Buyukozturk, S. (2002). Sosyal bilimler için veri analiz el kitabı [Handbook of data analysis in social sciences]. Ankara: PegemA.

Comrey, A.L. \& Lee, H.B. (1992). A first course in factor analysis. Hillsdale, NJ: Erlbaum.

Cutting, J.E. (1982). Two ecological perspectives: Gibson vs. Shaw and Turvey. American Journal of Psychology, 95, 199-222.

Demirel, O. ve Un, K. (1987). Egitim terimleri sozlugu [Dictionary of educational terms]. Ankara: Safak Matbaası.

Desolneux, A., Moisan, L. and Morel, J.M. (2008). From gestalt theory to image analysis: A probabilistic approach. Interdisciplinary Applied Mathematics, 34, 275.

Eidenberger, H. (2004). A new perspective on visual information retrieval. Retrieved October 1, 2009 from http://www.ims.tuwien.ac.at/media/documents/publications/ei2004-vir.pdf

Erinc, M.S. (1998). Sanatin boyutlari [Dimensions of art]. Istanbul: Cinar.

Findlay, J.M. \& Gilchrist, I.D. (2003). Active vision: The psychology of looking and seeing. Oxford, England: Oxford University Press.

Gibson, J. (1986). The ecological approach to visual perception. New York: Psychology Press.

Gillani, B.B. (2003). Learning theories and the design of e-learning environments. Lanham, MA: University Press of America

Gombrich, E. (2002). Art and illusion. Oxford, England: Phaidon.

Gordon, I.E. (2004). Theories of visual perception (3th edition). New York: Psychology Press.

Graham, L. (2008). Gestalt theory in interactive media design. Journal of Humanities and Social Sciences, 2(1), 1-12.

Gregory, R. L., Harris, J., \& Heard, P. (1995). The artful eye. Oxford, England: Oxford University Press.

Hsiaoa, S.W. \& Choub J.R. (2006). A Gestalt-like perceptual measure for home page design using a fuzzy entropy approach. International Journal of Human-Computer Studies, 64(2), 137-156.

Hutcheson, G. \& Sofroniou, N. (1999). The multivariate social scientist. London: Sage.

Jacobs, D.M. \& Michaels, C.F. (2007). Direct learning. Ecological Psychology, 19, 321-349.

Keser, H., Esgi, N. \& Simsek, A. (2003). Principles of educational web design. In G. Richards (Ed.), Proceedings of World Conference on E-Learning in Corporate, Government, Healthcare, and Higher Education 2003 (pp. 2011-2014). Chesapeake, VA: AACE.

Kline, P. (1994). An easy guide to factor analysis. New York: Routledge.

Koffka, K. (1935). Principles of gestalt psychology. New York: Harcourt, Brace.

Marr, D (1982). Vision. San Francisco, CA: Freeman \& Co. 
Messaris, Paul \& Moriarty, Sandra. (2005). Visual literacy theory. In K. Smith, S. Moriarty, G. Barbatsis, \& K. Kenney (Eds.), Handbook of Visual Communication (pp. 481-502). Mahwah: Lawrence Erlbaum Associates.

Michaels, C.F. \& Carello, C. (1981). Direct perception. Englewood Cliffs, NJ: Prentice Hall.

Mirielli, E. J. (2007). Using peer-evaluation in a website design course. Journal of Computing Sciences in Colleges, 22(4), 14-21.

Mirzoeff, N. (1998). The visual culture reader. New York: Routledge.

Moore, P. \& Fitz, C. (1993). Gestalt theory and instructional design. Journal of Technical Writing and Communication, 23(2), 137-157.

Mullet, K. \& Sano, D. (1995). Designing visual interfaces: Communication oriented techniques. Englewood Cliffs, NJ: Prentice Hall.

Pallant, J. (2001). SPSS survival manual. Maidenhead, PA: Open University Press.

Palmer, J. (2002). Website usability, design and performance metrics. Information Systems Research, 13(2), 151-167.

Postman, L. \& Tolman, E.C. (1959). Brunswick's probabilistic functionalism. In S. Koch (Ed.). Psychology: A study of a science (Vol. 1: Sensory, perceptual and physiological formulations). New York: McGraw-Hill.

Puustinen, M., Baker, M., \& Lund, K. (2006). Gestalt: A framework for redesign of educational software. Journal of Computer Assisted Learning, 22(1), 34-46.

Senemoglu N. (2005). Gelisim ogrenme ve ogretim (12. baski) [Development, learning and teaching (12th edition)]. Ankara: Gazi Kitabevi.

Taverna, M.A. (2003). Formative evaluation of web site design. Retrieved January 1, 2009 from http://www.designsinlearning.com/portfolio/portfoliohome.html

Treiblmaier, H. \& Pinterits, A. (2010). Developing metrics for web sites. Journal of Computer Information Systems, 50(3), 1-10.

Young, M. F., Barab, S. \& Garrett, S. (2000). Agent as detector: An ecological psychology perspective on learning by perceiving-acting systems. In. D. H. Jonassen \& S. M. Land (Eds.), Theoretical foundations of learning environments (pp. 147-172). Mahwah, NJ: Erlbaum.

Wade N. J. \& Swanston, M. (1991). Visual perception: An introduction. London: Routledge.

Withagen, R. \& van der Kamp, J. (2010). Towards a new ecological conception of perceptual information: Lessons from a developmental systems perspective. Human Movement Science, 29(1), 149-163.

Correspondence: Suzan Duygu Eristi, Assistant Professor, Department of Computer Education and Instructional Technologies, Faculty of Education, Anadolu University, Eskisehir, Turkey. 